\title{
PERANCANGAN DAN PENGEMBANGAN WEBSITE SMK PGRI 2 JOMBANG SEBAGAI MEDIA INFORMASI PROGRAM SEKOLAH
}

\author{
Titasari Rahmawati, Restu Hendriyani Magh'firoh \\ Institut Informatika Indonesia Surabaya \\ Email: tita@ikado.ac.id, restu@ikado.ac.id
}

\begin{abstract}
School is a medium or place for students to gain knowledge. So schools must provide good services to students, teachers and other staff. Services to students are not only services in academic matters that can support the success of students in the future. Information services that are accurate, current and fast are the demands of every public service today. So that SMK PGRI 2 Jombang as a Vocational School in the middle of Jombang has the same expectations as other schools that provide information quickly, accurately and always up to date. The information referred to is information about job vacancies. Currently, SMK PGRI 2 Jombang requires a website that can provide job information to all students. This website is expected by SMK PGRI 2 Jombang to assist the Job Vacancy Unit (BLK) in recording students who take the test at an institution that opens a vacancy. Because so far the BLK unit only records in Microsoft Excel, even though the number of students who are allowed to register is in the hundreds and the BLK unit consists of only 2 people. With the development of the website, it is expected to be able to help the BLK unit in selecting students who have qualifications in accordance with the requirements of the existing agencies.
\end{abstract}

Keywords: School, Students, Service, Information, Website, Job Vacancy, Qualifications.

\section{PENDAHULUAN}

Perkembangan ilmu pengetahuan dan teknologi saat ini sangat pesat, sehingga mengakibatkan banyak perubahan yang terjadi di berbagai bidang dalam kehidupan manusia. Tidak dapat dipungkiri, perkembangan teknologi tersebut membawa dampak yang positif jika digunakan dengan sebaik-baiknya. Dengan perkembangan teknologi membuat apa yang direaliasasikan manusia menjadi lebih efektif dan efisien. Khususnya teknologi komputer, dapat mempercepat segala pekerjaan sehingga semua pekerjaan dapat terselesaikan dalam waktu yang singkat. Saat ini dapat dirasakan bahwa kita hidup pada era masyarakat informasi yang berarti masyarakat sudah menggunakan banyak waktunya untuk mengakses informasi daripada menggunakan mesin industri. Informasi dihasilkan dari sebuah sistem informasi yang dikelola dengan seefektif mungkin sehingga dapat menghasilkan informasi yang tepat dan akurat. Sistem informasi akademik adalah suatu sistem yang dibangun untuk mengelola data-data akademik sehingga memberikan kemudahan kepada pengguna dalam kegiatan staf BLKistrasi akademik kampus secara online (Balelol,2013).

SMK PGRI 2 Jombang adalah salah satu sekolah swasta yang berlokasi di kota Jombang. Total siswa kelas keseluruhan adalah sekitar 1000 siswa yang berasal dari dalam kecamatan dan luar kecamatan jombang. Namun sebagian besar berasal dari luar kecamatan jombang. Selama ini informasi pada SMK PGRI 2 Jombang sudah menggunakan sistem informasi berbasis web namun desain tampilan website masih belum tersusun dengan baik sehingga baik siswa, calon siswa, dan orang tua kesulitan untuk mencari dan mengakses informasi website tersebut. Selain itu pihak pengelola website juga merasakan kesulitan dalam memasukkan berita dan data ke dalam website karena belum tersedianya fitur yang 
sistematis dari website misalnya dalam pengisian informasi lowongan kerja bagi kelas XII dan update informasi-informasi penting lainnya serta pihak sekolah kesulitan dalam melakukan sosialisasi jika pihak instansi/mitra membuka kesempatan kerja untuk siswa-siswi SMK PGRI 2 Jombang. Proses sosialisasi kebutuhan tenaga kerja dari instansi yang terkait selalu dilakukan dalam bentuk pertemuan langsung yang diselenggarakan di aula dimana hal ini kurang efisien dikarenakan bagian yang terkait atau disebut dengan BLK (Balai Lowongan Kerja) SMK PGRI 2 Jombang yang menyelenggarakan acara sosialisasi tersebut adalah tidak lain sebagai Pengajar sehingga acara sosialisasi sering terhambat dan tidak terlaksana karena staf BLK harus melakukan tugasnya sebagai pengajar.

Berdasarkan analisis yang dilakukan bersama mitra, solusi yang ditawarkan berupa perancangan website yang akan digunakan oleh BLK dalam menyeleksi siswa yang berhak mengikuti tes lowongan kerja pada instansi yang telah membuka lowongan. Untuk memudahkan pihak BLK dalam penggunaan website ke depannya, maka dalam kegiatan pengabdian ini akan dilakukan pelatihan kepada mitra atau dalam hal ini adalah BLK. Mitra dapat juga melihat modul atau panduan penggunaan website jika ke depannya mengalami kesulitan. Dengan demikian akan dicapai target luaran pengabdian ini antara lain memberikan kemudahan pihak mitra yaitu BLK dan alumni SMK PGRI 2 Jombang dalam menyampaikan dan mendapatkan informasi lowongan pekerjaan dan memberikan pengetahuan kepada mitra tentang teknologi informasi yang dapat memudahkan pekerjaan mereka sehari-hari.

\section{METODE PENGABDIAN}

Untuk mencapai perubahan pengetahuan dan pemahaman kepada mitra, maka perlu dilakukan halhal sebagai berikut.

a) Perencanaan

Kegiatan perencanaan sebagai berikut:

1. Melakukan survei lapangan ke beberapa sekolah, dan ketua berinisiatif untuk ke SMK PGRI 2 Jombang sebagai tempat dilaksanakannya kegiatan. Dikarenakan SMK PGRI 2 Jombang berdasarkan informasi dari beberapa narasumber, sekolah tersebut masih tertinggal dalam penggunaan teknologi padahal sekolah tersebut memiliki jumlah siswa yang tidak sedikit. Kemudian melakukan proses wawancara dan diskusi dengan pihak sekolah untuk identifikasi permasalahan.

2. Melakukan koordinasi dengan mitra (SMK PGRI 2 Jombang), dengan melakukan identifikasi masalah yang dilakukan sebagai langkah awal untuk merumuskan apa saja yang akan dijadikan bahan untuk perancangan sistem dan materi yang digunakan untuk pelatihan dengan mitra.

3. Melakukan pengumpulan data

4. Sosialisasi pengenalan sistem informasi (website) kepada mitra.

b) Pelaksanaan Tindakan

1. Pencarian pustaka untuk acuan materi yang digunakan selama kegiatan pengabdian ini.

2. Perancangan sistem website kemudian demonstrasi serta pelatihan secara langsung yang diberikan kepada staf BLK, siswa dan mitra sekolah SMK PGRI 2 Jombang. 
3. Pencarian pustaka untuk acuan materi yang digunakan selama kegiatan pengabdian ini.

4. Perancangan sistem website kemudian demonstrasi serta pelatihan secara langsung yang diberikan kepada staf BLK, siswa dan mitra sekolah SMK PGRI 2 Jombang.

5. Pelatihan website kepada mitra (SMK PGRI 2 Jombang). Pelatihan ini khususnya dilakukan kepada staf BLK, siswa atau calon alumni dan mitra sekolah.

c) Evaluasi

Evaluasi yang dilakukan melalui 2 tahap yaitu evaluasi sistem dan evaluasi pelatihan yang dilakukan pada mitra. Tim mengamati proses pelatihan yang telah dilakukan, apakah seluruh pengguna baik staf BLK, mitra dan siswa dapat menggunakan dengan mudah sistem informasi tersebut. Sedangkan evaluasi sistem adalah pengujian sistem website di sisi pengguna yaitu staf BLK, mitra dan alumni serta pengujian di sisi pengembang website.

Adapun tahapan kegiatan yang dilakukan sebagai berikut.

Tabel 1. Jadwal Pelaksanaan Kegiatan Pengabdian

\begin{tabular}{|c|c|c|c|c|c|}
\hline \multirow{2}{*}{ No } & \multirow{2}{*}{ Kegiatan } & \multicolumn{4}{|c|}{ Bulan } \\
\hline & & April & Mei Juni & Juli & Agustus \\
\hline & Survey Pendahuluan & $\mathrm{V}$ & $\mathrm{V}$ & & \\
\hline & Koordinasi dengan tim pengabdian & $\mathrm{V}$ & $\mathrm{V}$ & & \\
\hline & Identivikasi Masalah & & $\mathrm{V}$ & & \\
\hline & Pengumpulan Data & $\mathrm{V}$ & $\mathrm{V}$ & & \\
\hline 5 & Koordinasi Dengan Tim Developer Website & $\mathrm{V}$ & $\mathrm{V}$ & & \\
\hline 6 & Pembuatan Website & & $\mathrm{V} \quad \mathrm{V}$ & $\mathrm{V}$ & \\
\hline & Pengujian Website & & & $\mathrm{V}$ & $\mathrm{V}$ \\
\hline & Laporan & & & & $\mathrm{V}$ \\
\hline
\end{tabular}

Dalam membangun website SMK PGRI 2 Jombang ini dilakukan dengan beberapa tahapan yaitu:

1. Pembuatan desain tampilan atau layout website.

2. Melakukan pemrograman website.

3. Pengumpulan data-data yang dibutuhkan untuk ditampilkan pada website seperti:

a. Profil SMK PGRI 2 Jombang (Nama dan logo, arti logo, sejarah berdirinya)

b. Visi dan Misi

c. Kontak

d. Mitra usaha

e. Alamat lengkap dari sekolah

4. Melakukan web hosting.

Pelaksanaan kegiatan pengabdian kepada masyarakat dilakukan dalam 1 hari yaitu pada tanggal 10 Agustus 2019. Kegiatan ini dilakukan dengan membagi tugas pada ketua dan anggota agar kegiatan dapat berjalan sesuai rencana. Ketua tim bertugas dalam mengidentifikasi kebutuhan website, rancangan tampilan atau layout web, pengumpulan data-data yang dibutuhkan untuk membangun web SMK PGRI 2 Jombang, dan melakukan web hosting. Proses ini dilakukan dengan diskusi langsung bersama kepala sekolah, wakil kepala sekolah bagian kesiswaan yang nantinya sebagai staf BLK website guna 
memastikan perancangan web sesuai dengan kebutuhan yang diharapkan. Website yang dirancang nantinya dapat dikelola dengan baik oleh pihak yang berwenang dan diakses secara online dengan memanfaatkan fasilitas internet yang memadai.

Kemudian anggota tim bertugas untuk membuat dan menyiapkan bahan pelatihan yang akan diberikan ke staf BLK sekolah, siswa dan mitra sekolah. Pada pelaksanaannya tim akan memberikan pemaparan materi dengan memberikan slide power point dan modul yang berisi manual penggunaan website.

Secara bersamaan ketua akan mendemonstrasikan cara penggunaan website yang dimulai dari sisi staf BLK, lalu mitra kemudian siswa. Demonstrasi akan dilaksanakan di ruang laboratorium yang melibatkan 10 siswa sebagai sample dan staf BLK serta 1 orang mitra. Sehingga apa yang didemonstrasikan secara langsung akan dipraktekkan oleh peserta secara langsung. Dalam pelaksanaan pelatihan kepada mitra dibagi menjadi beberapa tahap antara lain.

a) Persiapan Pelatihan

Dari hasil pelaksanaan pengabdian ini luaran yang diperoleh adalah sebuah website sekolah yang dapat diakses secara online melalui URL www.smkpgri2jombang.sch.id. Website ini nantinya dikelola oleh sekolah SMK PGRI 2 Jombang. Untuk mempersiapkan pelatihan, tim pengabdian telah menyusun modul pelatihan yang akan menjadi pegangan dan pedoman pengguna selama kegiatan pelatihan. Selain itu pelaksana pelatihan harus mengakses URL website tersebut pada halaman browser pada perangkat komputer yang sudah disediakan sebelumnya.

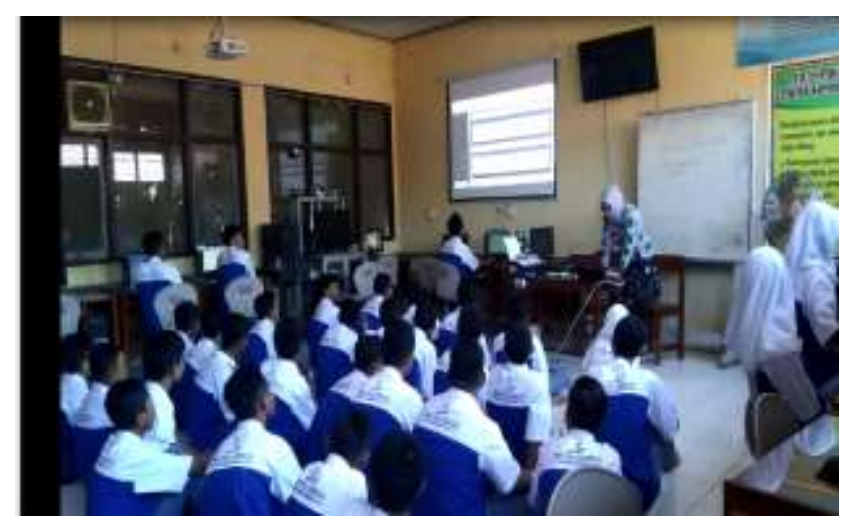

Gambar 1. Persiapan Pelatihan

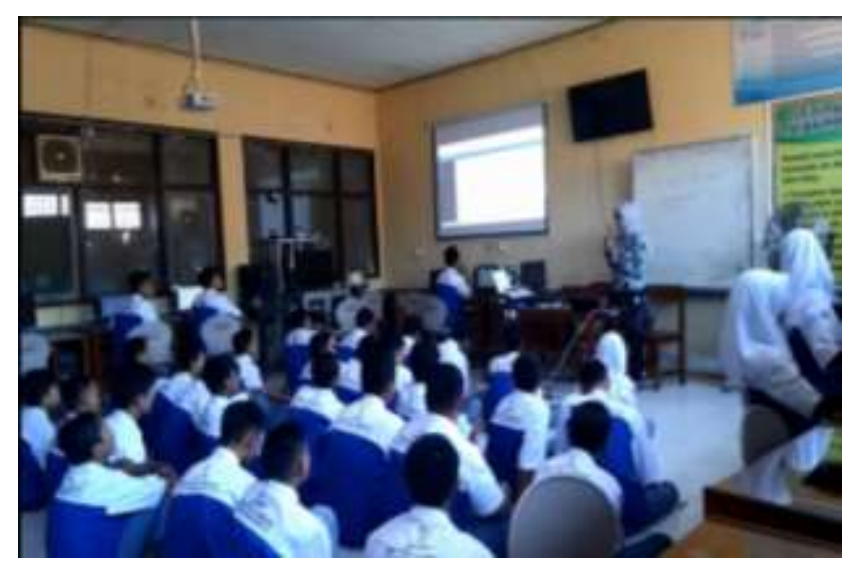

Gambar 2. Ketua Memberikan Pelatihan 
b) Pelaksanaan Pelatihan :

Ketika pengguna sudah mengetikkan alamat website pada address bar maka akan muncul tampilan sebagai berikut:

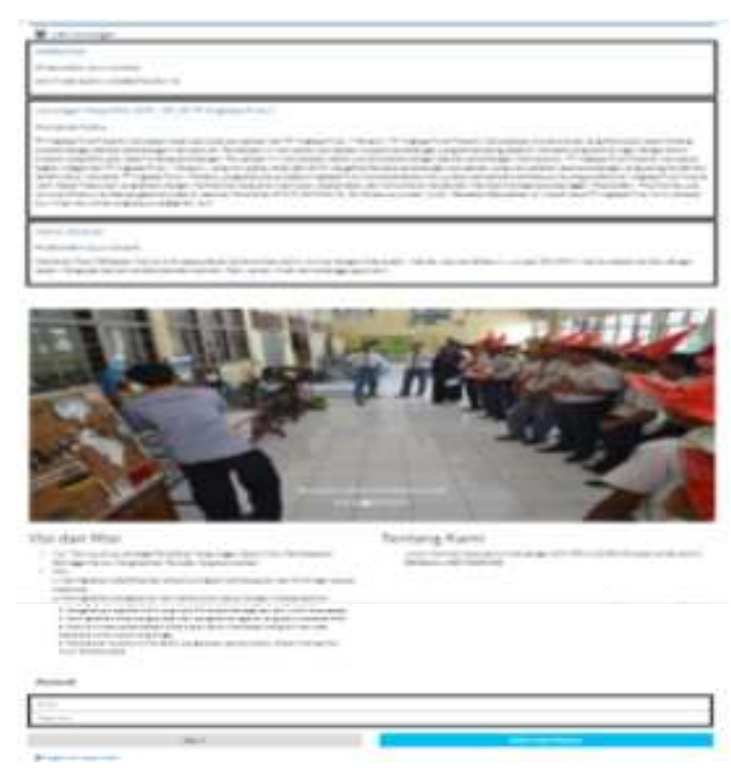

\section{Gambar 3. Halaman Utama Website}

Website memiliki 3 hak akses:

1) Hak Akses Admin

Pada halaman awal jika admin akan login harus mengisi email dan password yang sudah ditetapkan sebelumnya. Jika admin sudah login maka selanjutnya akan muncul halaman admin sebagai berikut:

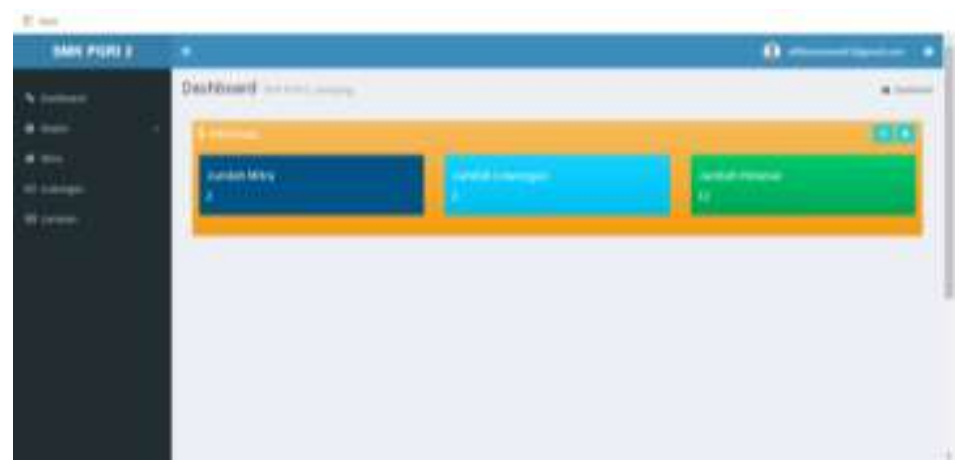

Gambar 4. Halaman awal admin

Dengan menggunakan hak akses admin maka akan ditampilkan submenu master yang berisi user untuk mengelola hak akses siswa dan mitra dan submenu mitra untuk mengelola data mitra kemudian lowongan serta lamaran.

a) Submenu user

Jika admin ingin menambahkan user siswa atau mitra dapat melalui submenu user. Admin harus menekan tombol plus di pojok kanan atas jika ingin menambahkan user baru kemudian admin harus mengisi form yang sudah disediakan. Semua field harus diisi lengkap jika tidak maka tidak dapat diproses. Namun jika admin ingin melakukan perubahan user yang sudah ada dapat langsung menekan link edit di sebelah kanan. 
b) Submenu siswa

Jika admin menekan submenu siswa maka akan tampil seperti pada gambar 4 di atas. Admin dapat menambah, mengubah serta menghapus data siswa. Admin juga dapat mengexport ke dalam bentuk excel dan menyesuaikannya sesuai dengan kebutuhan. Jika admin hanya membutuhkan kolom tertentu yang akan di export maka admin dapat menekan icon pojok kanan yaitu column chooser.

c) Submenu mitra

Jika admin hendak menambah mitra maka admin harus masuk ke dalam menu mitra kemudian admin harus melakukan tambah mitra dengan menekan tombol plus di atas kolom. Seperti pada submenu siswa sebelumnya data mitra dapat di-export ke dalam excel sehingga admin dapat mencetak data mitra.

d) Submenu lowongan

Selain mitra, admin juga dapat melakukan upload lowongan yang didapatkan dari mitra. Semua kolom harus diisi lengkap kecuali kolom keterangan dan situs. Seperti pada menu mitra dan siswa, untuk kolom lowongan juga dapat di-export ke dalam excel.

e) Submenu lamaran

Jika siswa telah melakukan lamaran maka admin dapat melihat data lamaran pada menu lamaran. Admin dapat mengetahui jenis lowongan yang dilamar siswa, nama pelamar, asal sekolah, tanggal melamar dan admin dapat melakukan tindakan selanjutnya apakah diterima atau ditolak.

2) Hak Akses Mitra

Mitra hanya memiliki menu lowongan. Halaman mitra dapat dilihat pada gambar 5.

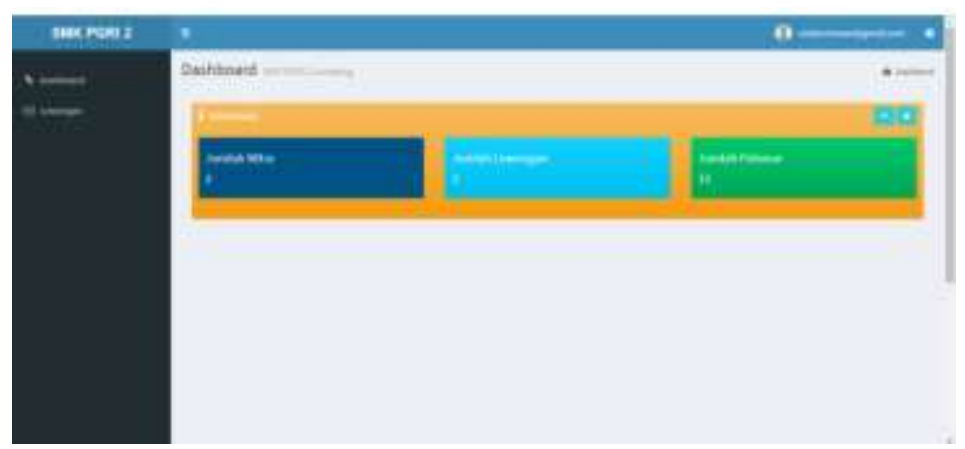

3) Pendaftaran

\section{Gambar 5. Halaman Mitra}

Alumni maupun bukan alumni SMK PGRI 2 Jombang dapat melamar dengan cara mengisi form pendaftaran seperti pada gambar di bawah ini. Jika alumni/bukan sudah melakukan pendaftaran maka jika ingin melamar pekerjaan pengguna cukup dengan sign in kemudian akan ditampilkan beberapa list lowongan pekerjaan yang up-to-date. 


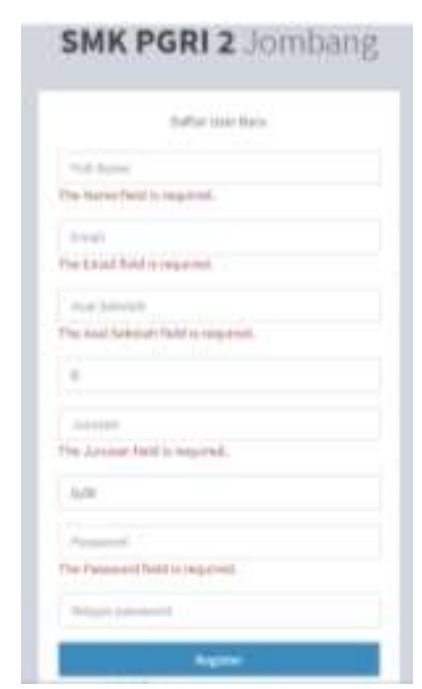

\section{Gambar 6. Halaman Daftar untuk Melamar Pekerjaan}

4) Hak Akses Pelamar

Berikut ini adalah halaman beranda pelamar, jika pelamar sudah berhasil mendaftar (mengisi form pendaftaran) maka pelamar dapat melakukan sign in sehingga dalam halaman beranda akan tampil list lowongan yang terbaru. Pelamar cukup memilih lowongan apa yang akan dilamar kemudian menekan tombol lamar. Jika pelamar lolos kualifikasi oleh staf BLK maka pelamar akan mendapatkan email pemberitahuan.

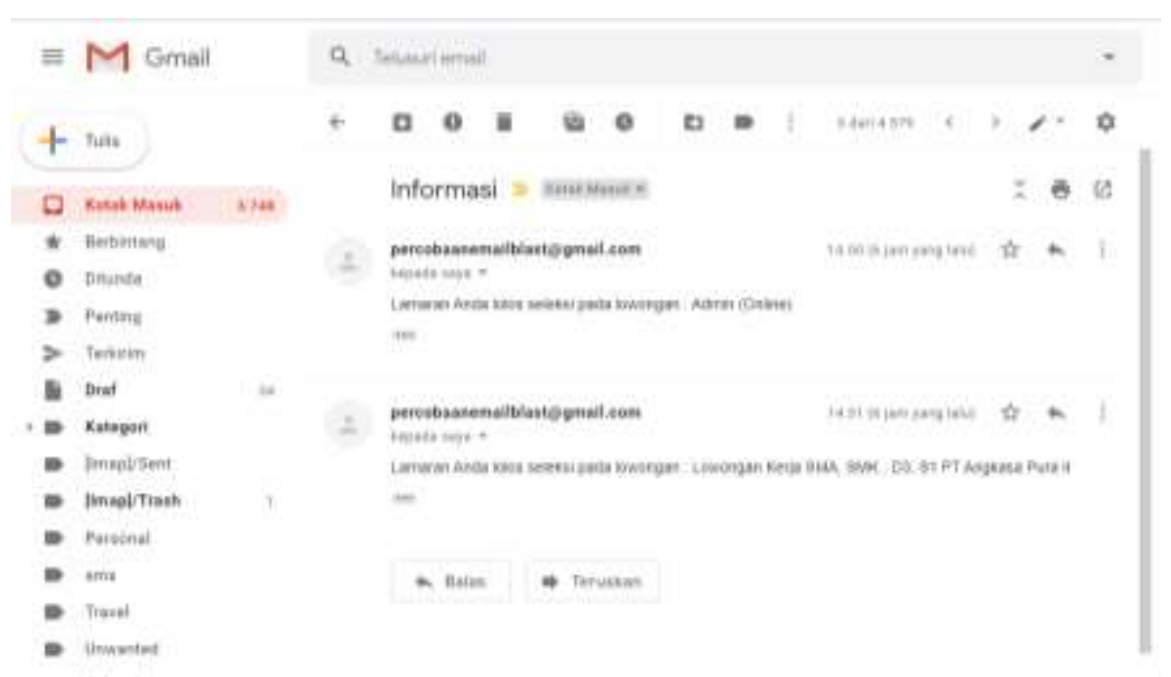

Gambar 7. Email Pemberitahuan Lolos Kualifikasi Lamaran.

\section{Kesimpulan}

\section{KESIMPULAN DAN SARAN}

Kegiatan pengabdian kepada masyarakat yang sudah dilakukan berupa diantaranya berupa sosialisasi pengenalan sistem informasi, uji coba website, dan pelatihan pemanfaatan website kepada mitra khususnya SMK PGRI 2 Jombang. Pelatihan diawali dengan pengenalan beberapa website yang sudah ada sebelumnya misalnya dengan menampilkan website-website sekolah lainnya, kemudian dilanjutkan dengan persiapan akses website dan kegiatan pelatihan. Dari kegiatan pengabdian berupa sosialisasi sistem informasi dapat disimpulkan bahwa calon alumni belum pernah memanfaatkan website 
sebagai sarana untuk mendapatkan informasi tentang sekolah, dari hasil beberapa pertanyaan yang diberikan sekolah kepada calon alumni sebagian besar calon alumni menggunakan internet hanya sebatas untuk media sosial. Kemudian kegiatan uji coba juga mendapatkan respon dan hasil yang baik dari staf BLK. Serta kegiatan pelatihan diperoleh hasil yang baik dan website dapat diterima oleh pihak sekolah.

\section{Saran}

Dari hasil diskusi dengan kepala sekolah, website yang dibuat akan dikembangkan nantinya untuk kegiatan promosi sekolah. Mengingat persaingan antar sekolah swasta saat ini sangat pesat sehingga dibutuhkan website yang dapat menginformasikan kepada calon siswa maupun orang tua agar mereka mengenal SMK PGRI 2 Jombang tidak hanya melalui surat kabar atau majalah. Melalui prestasiprestasinya kemudian peran Balai Lowongan Kerja yang selalu memberikan informasi lowongan yang up-to-date dapat membantu kegiatan promosi sekolah.

\section{UCAPAN TERIMAKASIH}

Ucapan terima kasih diberikan kepada Direktorat Riset dan Pengabdian Masyarakat (DRPM) yang telah memberikan dana Kegiatan Pengabdian kepada Masyarakat dengan Nomor: 001/SP2H/PPM/P3M/IKADO/IV/2019.

\section{DAFTAR PUSTAKA}

Sagala, S. 2010. Supervisi Pembelajaran dalam profesi pendidikan. Bandung: Alfabeta.

Balelol. 2013. Perancangan Sistem Informasi Berbasis Web.www.scribd.com (pdf). Diakses 22 Agustus 2018.

Faisal, R.M. 2014. Seri Belajar ASP.NET : Pengenalan ASP.NET Web API 